\title{
Ammonium uptake by seagrass communities: effects of oscillatory versus unidirectional flow
}

\author{
Florence I. M. Thomas*, Christopher D. Cornelisen \\ Department of Biology, University of South Florida, Tampa, Florida 33620, USA
}

\begin{abstract}
Nutrient dynamics of aquatic communities are dependent on the flux of nutrients to organisms within the communities. Flux is dependent on water column concentration and hydrodynamic factors that affect both advection of nutrients through the community and rates of diffusion at the surfaces of organisms. In this study, we measured rates of ammonium uptake for a seagrass community under various hydrodynamic conditions and determined the effects of water velocity and oscillatory flow on uptake rates. Experiments were conducted using a portable flume deployed in natural Thalassia testudinum communities. Uptake rate constants ranged from 9.9 to $25.4 \times 10^{-5} \mathrm{~m} \mathrm{~s}^{-1}$ and were $\sim 1.5$ times higher in oscillatory flow than in unidirectional flow. Uptake rate constants were positively dependent on both water velocity and turbulent energy in the water column. These results demonstrate the importance of hydrodynamics on biogeochemical cycling in seagrass beds and provide evidence of the efficacy of merging research on hydrodynamics and biogeochemistry in understanding nutrient processes in complex nearshore communities.
\end{abstract}

KEY WORDS: Oscillatory flow $\cdot$ Water velocity $\cdot$ Hydrodynamics $\cdot$ Nutrients $\cdot$ Ammonium uptake Seagrass $\cdot$ Mass transfer $\cdot$ Submerged aquatic vegetation

\section{INTRODUCTION}

Seagrass communities are highly productive (e.g. Moncreiff et al. 1992, Duarte \& Chiscano 1999) and comprised of numerous organisms whose metabolic needs are dependent on the transport of dissolved chemicals within the seagrass canopy. Seagrasses are found primarily in shallow water along coastal margins and within estuaries which are physically dynamic and exposed to both tide- and wave-generated currents (e.g. Koch \& Gust 1999). Canopies formed by seagrass plants collectively attenuate water flow within the canopy (Fonseca et al. 1982, Gambi et al. 1990, Ackerman \& Okubo 1993) and can enhance flow over and around the bed (Gambi et al. 1990, Koch \& Gust 1999). These effects on water flow influence important ecological processes such as sediment retention (Fonseca \& Fisher 1986, Gacia et al. 1999), transport and recruitment of larvae (Eckman 1987, Grizzle et al. 1996), photosynthesis (Fonseca \& Kenworthy 1987, Koch 1994) and the transport and uptake of nutrients (Thomas et al. 2000). Our current state of knowledge on the effects of water flow on these processes is primarily based on studies involving flume experiments with unidirectional flow. However, in addition to unidirectional flow driven by tides, waves often contribute an oscillatory component to the water flowing over seagrass communities (e.g. Fonseca \& Kenworthy 1987, Worcester 1995, Koch \& Gust 1999). The effect of this oscillatory flow on important ecological processes in seagrass communities, such as nutrient delivery and uptake, remains largely unknown.

The velocity of unidirectional flow affects the flux of nutrients to the benthos by determining the rate of nutrient advection over the bottom and by decreasing the diffusive boundary layer at the uptake surfaces of organisms (e.g. Bilger \& Atkinson 1992, Patterson 1992). This effect of velocity on nutrient uptake has been demonstrated for individual organisms (e.g. Gerard 1982, Hurd et al. 1996, Cornelisen \& Thomas 2002) and groups of organisms (e.g. Bilger \& Atkinson 1992, Larned \& Atkinson 1997, Thomas \& Atkinson 1997). In 
addition, field flume experiments conducted in entire seagrass communities and in unidirectional flow have demonstrated that uptake rates of an important nutrient, ammonium, is positively dependent on water velocity (Thomas et al. 2000).

In addition to velocity, other characteristics of water flow in a habitat can affect the delivery of metabolically important chemicals. Oscillation in the flow increases turbulence in the boundary layer over the uptake surface. Turbulence increases momentum transfer which, in turn, thins the diffusive boundary layer at the uptake surfaces of organisms within the community; thus oscillatory flow is likely to enhance chemical transfer to benthic organisms (e.g. Denny 1988, Hearn et al. 2001). Measurements of the effects of oscillatory flow on chemically dependent metabolic processes of the benthos have been relatively rare, although oscillatory flow has been shown to increase photosynthesis (Carpenter et al. 1991) and nitrogen fixation (Williams \& Carpenter 1998) of benthic microalgae in a laboratory flume. In addition, Hearn et al. (2001) demonstrated that increases in shear stress and energy dissipation as a result of wave-driven oscillation in flow could enhance uptake rates beyond those predicted by equations describing transport processes for unidirectional flow. Results of their analysis indicate that uptake rates of nutrients by coral reefs are positively related to bulk water velocity $\left(U_{\mathrm{b}}\right)$, energy dissipation $(\varepsilon)$, and shear stress $(\tau)$.

The flow in most seagrass habitats has a wavedriven oscillatory component, which is likely to influence transport of nutrients in a similar fashion to that observed by Hearn et al. (2001) for coral reefs. Seagrass canopies are flexible; however, allowing seagrass blades to bend with increasing flow velocity. Thus, the friction imposed by the benthos on the water decreases with increasing water velocity at a faster rate than would be expected for a solid non-flexible surface such as a coral reef (Thomas et al. 2000). Flexibility of the grasses also creates regions of variableflow environments within the canopy (e.g. Ackerman \& Okubo 1993). Thus, it is likely that uptake rates of nutrients by seagrass beds will be affected by the energy associated with oscillatory flow, but the relationship between uptake rates and characteristics of flow may be different than those described for coral reefs (Hearn et al. 2001).

In this study, we measured rates of ammonium uptake for a seagrass community in the field using a portable field flume (Thomas et al. 2000) and compared uptake rates for experiments conducted under oscillatory and unidirectional flow. Uptake rate constants were analyzed in terms of hydrodynamic characteristics over the seagrass canopy including velocity, speed, and turbulent energy. In addition, we applied empirical models that describe mass transfer processes (see Bilger and Atkinson 1992) to estimate the efficiency of these seagrass communities at removing ammonium from the water column and compared these estimates to our experimental data.

\section{MATERIALS AND METHODS}

To investigate the effects of oscillatory water flow on ammonium uptake by seagrass communities, a series of field flume experiments were conducted in natural beds of Thalassia testudinum. Experiments were completed over $5 \mathrm{~d}$ in 1998 (25 to 29 October) and $10 \mathrm{~d}$ in 1999 (6 to 16 June) in St. Joseph Bay, Florida, USA. St. Joseph Bay is located in the NE Gulf of Mexico along the panhandle of Florida and is inhabited by extensive beds of Halodule wrightii, Syringodium filiforme, and Thalassia testudinum. A total of 27 ammonium uptake experiments were conducted in oscillatory flow, 18 in beds of T. testudinum, and 9 in bare sand as a control for planktonic uptake and flume leakage; 7 experiments were also conducted in unidirectional flow in $T$. testudinum communities. In addition, data collected from 7 unidirectional experiments conducted previously at the same field site (Thomas et al. 2000) were used in the comparison of unidirectional and oscillatory flow on ammonium uptake. Shoot densities ranged from 1600 to 3100 shoots $\mathrm{m}^{-2}$ and canopy heights from 22 to $27 \mathrm{~cm}$, which are values similar to those reported by Thomas et al. (2000).

The field flume effectively isolates $3.7 \mathrm{~m}^{2}$ of benthos and has been used in a previous study in which the effects of unidirectional flow on ammonium uptake by seagrass communities were demonstrated (see Thomas et al. 2000 for design description). The flume design was slightly modified for this study by installing 2 (rather than 1) electric motors that were faced in opposite directions and alternately powered to impose oscillatory flow on the isolated portion of the community. A timer and relay switch were used to alternate power to each of the motors and maintain a constant oscillation period. The mean period for 1 full oscillation during these experiments was $\sim 18.5 \mathrm{~s}$ (SD 3.9, $\mathrm{n}=40$ ), or a frequency range of 0.04 to $0.07 \mathrm{~Hz}$. This frequency range is at the low end of that reported for energy spectra within St. Joseph's Bay (Koch \& Gust 1999) and within the range of those measured in other seagrass beds (Verduin \& Backhaus 2000). For unidirectional experiments conducted during this study, only 1 of the 2 motors was powered. The motor(s) were set at a constant velocity between (0.01 and $0.27 \mathrm{~m} \mathrm{~s}^{-1}$ ) for each experiment. The velocity, type of flow (unidirectional or oscillatory) and community (seagrass or sand) for each experiment 
was randomly selected from a pool of predetermined conditions.

Experiments were conducted in depths that were below the flume sides $(<0.8 \mathrm{~m})$ and care was taken to ensure there was no leakage from the flume by (1) taking ambient water samples before each experiment and in the water surrounding the flume during experiments, (2) using rhodamine dye following experiments for a visual test of flume leakage, and (3) reviewing data from sand experiments which were void of seagrasses and associated organisms. After placing the flume over a section of the bottom, a spike of ammonium (as $20 \mu \mathrm{mol} \mathrm{l}^{-1}$ ammonium sulfate) was added slowly to the flume (over $\sim 5 \mathrm{~min}$ ) and allowed to mix thoroughly so that the $\mathrm{NH}_{4}{ }^{+}$concentration at the beginning of each experiment was $\sim 6 \mu \mathrm{mol} \mathrm{l}^{-1}$. During each experiment, water to be sampled was continuously removed from the flume with a submersible pump placed at the opening to the motor box so that it sampled well-mixed water. Samples were collected in 11 sample bottles (Nalgene) over a series of 6 to 7 sampling periods (ranging from 2 min to 10 min duration). Each $1 \mathrm{l}$ bottle represented a sampling period, and water within these bottles was filtered and placed in smaller $60 \mathrm{ml}$ bottles and frozen until samples were analyzed. A more detailed description of methods for water sample collection is provided in Thomas et al. (2000). The duration of experiments ( 45 min) was based on previous data (Thomas et al. 2000), which revealed that these communities deplete ammonium rapidly from the water column, especially at higher velocities.

Ammonium concentrations were measured with an auto-analyzer (Alpkem) using standard techniques (Strickland \& Parsons 1972) to an accuracy of $0.05 \mu \mathrm{mol}$ $\mathrm{I}^{-1}$. Uptake rate constants $\left(S\right.$ in units s${ }^{-1}$ ) were calculated by first determining a first-order rate constant that described the decline in ammonium concentration in the flume for each experiment. The first-order rate constant was calculated as $k(C)=-\mathrm{d} C / \mathrm{d} t$, where $C$ is the concentration of ammonium, $t$ is time, and $k$ is the first-order rate constant in units of $\mathrm{s}^{-1}$. Each value of $k$ was normalized to the volume of water in the flume $(V)$ and the planar area of community $(A)$ isolated by the flume to calculate an uptake rate constant, $S(S=$ $k V / A)$. The 2-dimensional area of benthos enclosed by the flume is used for normalization because the engineering approach used in this and previous studies (e.g. Atkinson \& Bilger 1992, Thomas \& Atkinson 1997, Thomas et al. 2000) describes the effects of bottom roughness (i.e. the biota on the benthos) on chemical transport, rather than the total area available for nutrient uptake (see Thomas et al. 2000 for discussion). Basically, the approach provides an estimate of the effects of the roughness created by the benthos on the flow characteristics in the water column, which in turn determines the flux of nutrients from the water column to a square area of the benthos. A measure of total surface area available for uptake is unnecessary because the approach describes the maximum rate of flux to the planar area of the benthos with the specific roughness (represented in the friction coefficient and shear stress) measured for that surface.

Water velocity was measured during each experiment using an Acoustic Doppler velocimeter (Field

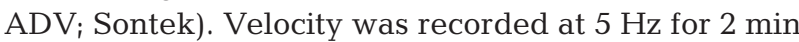
$(\mathrm{n}=600)$ at mid-water depth equidistant between the canopy and the water's surface. Velocity data were used to estimate several hydrodynamic characteristics that influence the transport of nutrients to seagrass communities, including (1) mean velocity in longitudinal $(\bar{U})$, transverse $(\bar{V})$, and vertical $(\bar{W})$ flow directions, (2) mean modulus of the velocity vector $(|\vec{U}|),(3)$ mean flow speed in the + and - longitudinal direction $(|U|)$, and (4) total turbulent energy $(K)$.

Bulk velocity $\left(U_{\mathrm{b}}\right)$ was estimated as the mean of the velocity in the longitudinal direction $\bar{U}$. For unidirectional experiments bulk velocity and flow speed are equivalent; however, for oscillatory experiments water is moving in both the up- and downstream directions. Thus, the speed of the water $(|U|)$ exceeds the bulk movement of water $\left(U_{\mathrm{b}}\right)$ over the benthos in a given direction. Therefore, for oscillatory experiments we used the mean of the absolute value of velocity in the longitudinal direction $|U|$ as an estimate of flow speed. In both oscillatory and unidirectional experiments, flow in the longitudinal direction was predominant and accounted for the majority of the modulus of the flow vector $\left(|\vec{U}|=1.08 \cdot|U|+0.002 ; \mathrm{r}^{2}=0.99 ; \mathrm{p}<0.001, \mathrm{n}=\right.$ $25)$. We chose to use $\bar{U}$ rather than the modulus so that we could compare unidirectional data to previous research (Thomas \& Atkinson 1997, Thomas et al. 2000). Total turbulent energy was calculated from the mean fluctuations in velocity among the velocity components using the equation $K=0.5\left(U^{\prime 2}+V^{\prime 2}+W^{\prime 2}\right.$ ) (see Denny 1988, Nikora et al. 1998). Turbulent energy contributes to transfer of momentum to the benthos, which in turn affects rates of chemical transport. Estimates of $K$ were calculated to evaluate variations in turbulence between unidirectional and oscillatory experiments and the effects of turbulence on nutrient uptake.

\section{RESULTS}

The regressions of ammonium concentration versus time used to determine the first-order rate constant $(k)$ were significant $(p<0.01)$ for all oscillatory and unidirectional experiments conducted in beds of Thalassia testudinum. Regressions had a mean $\mathrm{r}^{2}$ of 0.96 ( $\mathrm{SD}=$ 
0.05 , range $=0.86$ to $0.99, \mathrm{n}=18)$ and $0.94(\mathrm{SD}=0.2$, range $=0.90$ to $0.97, \mathrm{n}=7$ ) for oscillatory and unidirectional experiments, respectively. Uptake rate constants $(\mathrm{S} ; \mathrm{S}=k V / A)$ for experiments conducted with oscillatory water flow were enhanced relative to those conducted in unidirectional flow (Fig. 1). At bulk-water
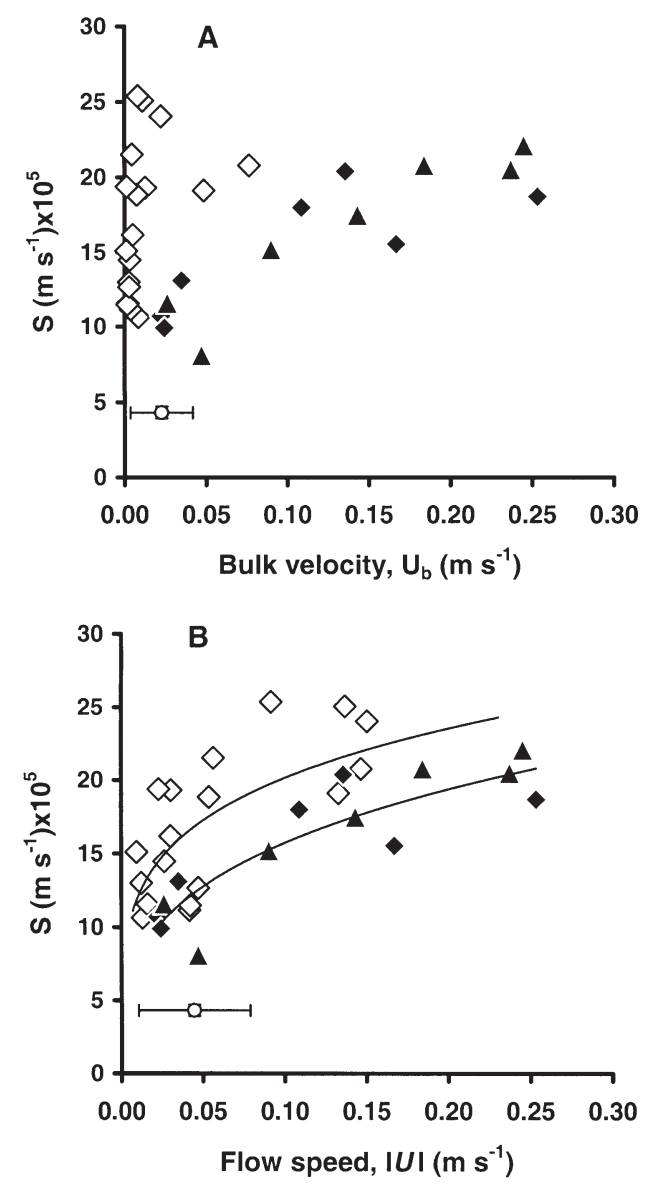

Fig. 1. Thalassia testudinum. Ammonium uptake rate constants $(S)$ as a function of (A) bulk velocity $\left(U_{\mathrm{b}}\right)$ and (B) flow speed $|\bar{U}|$ for oscillatory experiments $(\diamond)$ and unidirectional experiments $(\diamond)$ from this study and for unidirectional experiments (४) from Thomas et al. (2000). A single point (O) represents the mean value of the uptake rate constants for 7 experiments conducted in bare sand plotted at the mean velocity of these experiments (error bars $=1 \mathrm{SD}$ ). (A) $S$ is positively dependent on $U_{\mathrm{b}}$ in oscillatory $\left(S \times 10^{5}=32.3 U_{\mathrm{b}}^{0.13}\right.$, CLs on slope are 0.02 to $0.24, \mathrm{r}^{2}=0.28, \mathrm{p}<0.05, \mathrm{n}=18$ ) and unidirectional $\left(S \times 10^{5}=31.5 U_{\mathrm{b}}^{0.30}\right.$, CLs on slope are 0.19 to $0.41, \mathrm{r}^{2}=$ $0.76, \mathrm{p}<0.001, \mathrm{n}=14$ ) flow; there was no significant difference between unidirectional data sets (ANCOVA, $p>0.05$ ). (B) $S$ is positively dependent on flow speed for both unidirectional and oscillatory flow; the effect of flow speed $(|\bar{U}|)$ is the same as in (A) for unidirectional experiments and for oscillatory flow is $S \times 10^{5}=33.8|\bar{U}|^{0.22}$ (CLs on slope are 0.10 to 0.35 , $\mathrm{r}^{2}=0.46, \mathrm{p}<0.01, \mathrm{n}=18$ ). Flow speed had a similar affect on uptake in both treatments (homogeneity of slopes, $\mathrm{p}=0.35$ ); however, uptake rate constants were higher in oscillatory flow (ANCOVA, $\ln S$ vs $\ln |\bar{U}|, \mathrm{p}<0.001$ ) velocities $\left(U_{\mathrm{b}}\right)$ below $10 \mathrm{~cm} \mathrm{~s}^{-1}$, uptake rate constants $(S)$ for experiments conducted in oscillatory flow (mean $\left.=17.2 \times 10^{-5}, \mathrm{SD}=5.0, \mathrm{n}=18\right)$ were 1.5 times those conducted in unidirectional flow (mean $=11.4 \times$ $10^{-5}, \mathrm{SD}=2.5, \mathrm{n}=6$ ). In both oscillatory and unidirectional experiments, mean bulk velocity $\left(U_{\mathrm{b}}\right)$ had a positive effect on ammonium uptake by $T$. testudinum communities (Fig. 1A). The dependence of uptake rate constants $(S)$ on $U_{\mathrm{b}}$ in the oscillatory experiments was lower and less evident (as demonstrated by a low $\mathrm{r}^{2}$ of 0.28 ) than in unidirectional experiments.

Values for $S$ were higher in oscillatory than in unidirectional flow when uptake rate constants $(S)$ were compared to flow speed $(|U|)$ (Fig. 1B). For both oscillatory and unidirectional experiments, the slope of $S$ versus $|U|$ were similar; however, the intercept was higher for the oscillatory than the unidirectional experiments (ANCOVA, ln $S$ vs $\ln |U|, \mathrm{p}<0.001$ ). The dependence of $S$ on $|U|$ in these seagrass communities was on the order of $0.3\left(S \cong|U|^{0.30} ;\right.$ Fig. $\left.1 \mathrm{~B}\right)$. There was no dependence between uptake rate constants and flow speed in the sand experiments $\left[4.7(|U|)^{0.01}, \mathrm{r}^{2}=\right.$ $0.00, \mathrm{p}=0.88, \mathrm{n}=7$ ], and 2 of the 9 experiments showed no significant uptake. Uptake rate constants for sand were lower than $5 \times 10^{-5}\left(\mathrm{~m} \mathrm{~s}^{-1}\right)$ and consistent with those for unidirectional experiments by Thomas et al. (2000).

At a given bulk velocity $\left(U_{\mathrm{b}}\right)$, turbulent energy $(K)$ was greater in oscillatory flow $\left[K\left(\mathrm{~m} \mathrm{~s}^{-1}\right]^{2}=0.22 \cdot U_{\mathrm{b}}+\right.$ $\left.0.0019 ; \mathrm{r}^{2}=0.45 ; \mathrm{p}<0.001, \mathrm{n}=36\right)$ than in unidirectional flow $\left[K\left(\mathrm{~m} \mathrm{~s}^{-1}\right)^{2}=0.03 U_{\mathrm{b}}-0.0006 ; \mathrm{r}^{2}=0.83 ; \mathrm{p}<\right.$ $0.001, \mathrm{n}=9$ ). In addition, an analysis of the power spectra for 2 experiments with similar flow speeds indicate that in oscillatory flow there was more energy generated at frequencies below $0.2 \mathrm{~Hz}$ than in unidirectional flow (Fig. 2B). Uptake rate constants $(S)$ were dependent on turbulent energy for oscillatory flow ( $p<$ 0.001); however, for unidirectional flow the regression was not significant. For all the experiments combined, uptake rate constants were dependent on turbulent energy [Fig. $3 ; \mathrm{S} \times 10^{5}\left(\mathrm{~m} \mathrm{~s}^{-1}\right)=36.1(K)^{0.12} ; \mathrm{r}^{2}=0.47$; $\mathrm{p}<0.001, \mathrm{n}=25$ ].

\section{DISCUSSION}

Rate constants for ammonium uptake by seagrass Thalassia testudinum communities measured in field flume experiments were dependent on bulk velocity $\left(U_{\mathrm{b}}\right)$ and flow speed $(|U|)$. The results of experiments conducted in unidirectional flow are consistent with past research (Thomas et al. 2000) and indicate that measurements of $U_{\mathrm{b}}$ are relatively good predictors of rate constants for ammonium uptake under conditions where flow is mainly unidirectional (i.e. tide- 

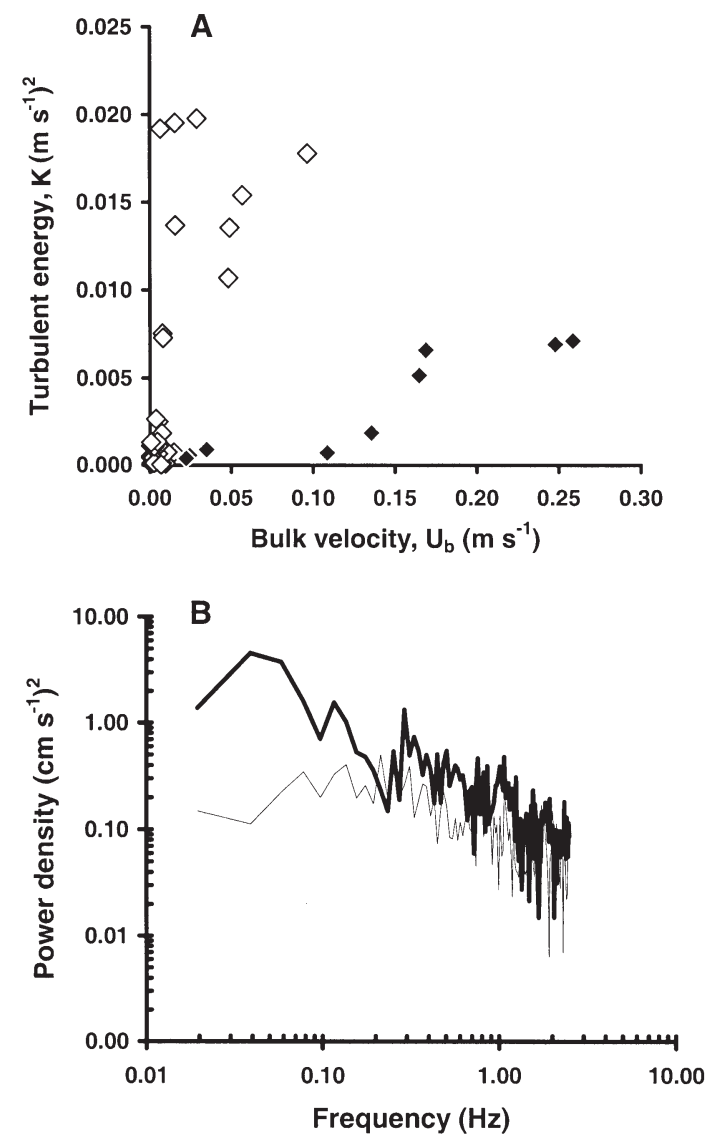

Fig. 2. Thalassia testudinum. (A) Total turbulent energy $(K)$ as a function of bulk velocity $\left(U_{\mathrm{b}}\right)$ for oscillatory experiments $(\diamond)$ and unidirectional experiments $(\diamond)$ from this study. Relationship between $K$ and $U_{\mathrm{b}}$ was steeper in oscillatory flow $\left(K=0.22 \cdot U_{\mathrm{b}}+0.0019 ; \mathrm{r}^{2}=0.45 ; \mathrm{p}<0.001, \mathrm{n}=36\right)$ than in unidirectional flow $\left(K=0.03 \cdot U_{\mathrm{b}}-0.0006 ; \mathrm{r}^{2}=0.83 ; \mathrm{p}<0.001\right.$, $\mathrm{n}=9$ ). (B) Power spectra for 2 experiments, 1 oscillatory at a flow speed of $0.09 \mathrm{~m} \mathrm{~s}^{-1}(-)$ and 1 unidirectional at a flow speed of $0.11 \mathrm{~m} \mathrm{~s}^{-1}(-)$. Higher energy between frequencies 0.04 and 0.07 for the oscillatory experiment coincides with the frequency of the imposed oscillation

dominated). When the flow has a significant oscillatory component, however, bulk velocity alone is not a good predictor of uptake rate constants (Fig. 1A). For the experiments conducted with oscillatory flow, uptake was dependent on the speed of the water flow in the predominant direction of flow $|U|$ rather than the average bulk velocity $U_{\mathrm{b}}$ (Fig.1). This result is not surprising, because the average bulk velocity measures the movement of a body of water in a direction rather than the actual speed of water flowing over the organisms. Increased flow speed above a canopy is correlated to higher flows within the canopy where the uptake surfaces of organisms are located (F.I.M.T. \& C.D.C. unpubl. data), and higher flow thins the diffusive boundary layer regardless of the direction of water flow. Therefore, the speed of the water above the canopy in the longitudinal direction $|U|$ gives a better indication of the amount of flow experienced at uptake surfaces within the community than bulk velocity and provides a relatively good estimate of flow effects on transport rates (Fig. 1B).

Despite the relatively good fit between measurements of flow speed $(|U|)$ and uptake rate constants $(S)$, comparing $(S)$ to $|U|$ is a simplification. The turbulent energy in the flow $(K)$ contributes to the transport of momentum to the bottom. As indicated by our results, uptake rate constants were dependent on bulk velocity (Fig. 1) and turbulent energy (Fig. 3), which supports the contention that ammonium uptake by seagrass communities is diffusion-limited (Thomas et al. 2000). The effects of turbulent energy on uptake rate constants $(S)$ can be seen by comparing experiments conducted in oscillatory and unidirectional flow (Fig. 1). At a given bulk velocity, $S$ is higher in oscillatory than in unidirectional flow, as is turbulent energy (Fig. 2). Because uptake rate constants are also dependent on turbulent energy (Fig. 3), the differences in $S$ between treatments can be accounted for by higher turbulent energy in oscillatory than unidirectional flow (Fig. 2). This dependence of chemical uptake on turbulent energy in seagrass communities is comparable to that demonstrated for coral communities (Hearn et al. 2001), and may explain the higher rates of nitrogen fixation (Williams \& Carpenter 1998) and photosynthesis (Carpenter et al. 1991) in oscillatory flow than in unidirectional flow reported for algal turf communities.

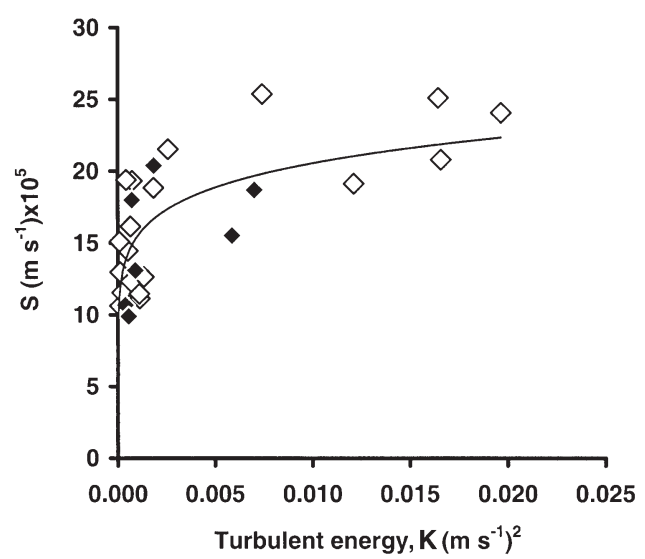

Fig. 3. Thalassia testudinum. Ammonium uptake rate constants $(S)$ as a function of total turbulent energy $(K)$ for oscillatory experiments $(\diamond)$ and unidirectional experiments $(\diamond)$ from this study. Uptake rate constants were dependent on turbulent energy for oscillatory flow $\left[S \times 10^{5}=36.5(K)^{0.12} ; \mathrm{r}^{2}=0.53\right.$; $\mathrm{p}<0.001, \mathrm{n}=18]$, however, for unidirectional flow the regression was not significant. For all experiments combined, the relationship between the uptake rate constants and turbulent energy (represented by the line) was positive and significant $\left[S \times 10^{5}=36.1(K)^{0.12} ; \mathrm{r}^{2}=0.47 ; \mathrm{p}<0.001, \mathrm{n}=25\right]$ 


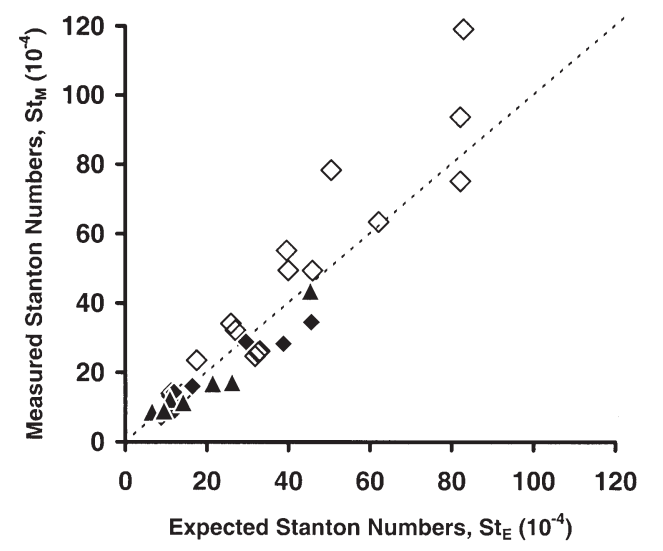

Fig. 4. Thalassia testudinum. Measured versus expected Stanton numbers communities for oscillatory experiments $(\diamond)$ unidirectional experiments $(\diamond)$ from this study and for unidirectional experiments (ム) from Thomas et al. (2000). Measured Stanton numbers $\left(S t_{\mathrm{M}}\right)$ are calculated from experimental values of uptake rate constants $(S)$ and water velocity $\left(U_{\mathrm{b}}\right)$ measured in the flume during each experiment $\left(S t_{\mathrm{M}}=S / U_{\mathrm{b}}\right.$ for unidirectional experiments or $S /|\bar{U}|$ for oscillatory experiments); expected Stanton numbers $\left(S t_{\mathrm{E}}\right)$ are calculated from measured friction coefficients and empirically derived equations describing heat transfer to non-biotic surfaces (see Bilger \& Atkinson 1992, Thomas et al. 2000). Stanton number is the ratio of the flux to the surface divided by advection by the surface and represents the effective capacity (efficiency) of a surface to remove a chemical from the water column. Oscillatory flow enhances the efficiency of ammonium uptake by seagrass communities, as indicated by the larger Stanton numbers. Dashed line represents 1:1 ratio

Despite the complexity of mechanisms controlling nutrient dynamics of benthic communities, models describing transport processes to rough surfaces have provided relatively good estimates of the efficiency of benthic surfaces at removing specific nutrients (Baird \& Atkinson 1997, Thomas \& Atkinson 1997, Larned \& Atkinson 1998, Thomas et al. 2000). The approach used in these studies involves the calculation of a dimensionless number (the Stanton number) that relates uptake rate constants $(S)$ to the rate of advection of nutrients over the surface. These measured Stanton numbers represent the efficiency of the community at removing nutrients from the water column and can be estimated from empirically derived engineering equations (Atkinson \& Bilger 1992, Bilger \& Atkinson 1992). A specific set of these equations (e.g. Thomas \& Atkinson 1997) provides a close estimate of Stanton numbers measured for assemblages of coral reef organisms (Baird \& Atkinson 1997, Thomas \& Atkinson 1997) and for seagrass communities measured in a field flume (Thomas et al. 2000). Estimates of the Stanton number along with measurements of nutrient concentrations and hydrodynamic characteristics of benthic habitats provide a means of estimating the capacity of the ben- thos to remove a specific chemical (i.e. nutrient) from the water column (see Thomas et al. 2000).

The empirically derived equations used in these studies were developed to examine heat and mass transfer to rough surfaces in unidirectional flow. However, if flow speed $|U|$ is used in these equations rather than bulk flow $\left(U_{\mathrm{b}}\right)$ they provide a relatively good estimate of the Stanton number for the experiments we conducted in both oscillatory and unidirectional flow (Fig. 4). Development of more complete models describing mass transfer of nutrients to seagrassdominated communities will require measurements of nutrient uptake rates combined with an analysis of velocity profiles. Velocity data from this study were collected at a single height above the reference bed, which limits our interpretive power. Further, data presented in this paper are limited to a single wave frequency. The frequency of oscillation influences energy; therefore, data obtained over a range of wave conditions would expand the application of these models to a wider range of field conditions.

The mechanisms underlying nutrient uptake by benthic communities are complex. Nonetheless, the results of these experiments provide evidence that uptake of ammonium by seagrass communities is dependent on water flow characteristics, including water velocity and turbulent energy. Thus, the capacity of seagrass beds to remove ammonium from the water column is probably higher during ebb and flood tides and/or periods of high wave energy than during slack tides and calm conditions. In addition to the effects of hydrodynamics on diffusion-limited uptake, the concentration of ammonium is likely to increase in the water column during these events due to enhanced anthropogenic loading, porewater fluxes and wave-generated resuspension of nutrients that can accompany tides and storm events (e.g. Staver et al. 1996, Morin \& Morse 1999, Oldham \& Lavery 1999, Glasgow \& Burkholder 2000). For example, in St. Joseph's Bay we have recorded an increase in ammonium concentration from 0.5 to $9 \mu \mathrm{m}$ after a major storm event (F.I.M.T. \& C.D.C unpubl. data).

Nutrient dynamics of aquatic communities are dependent on the interplay between factors that control water column nutrient concentration and hydrodynamic factors that influence characteristics of the diffusive boundary layer at the uptake surfaces within the communities. The merger of hydrodynamic models with studies of biogeochemical cycling is therefore crucial for accurately describing nutrient cycling in dynamic nearshore environments (see Duarte \& Piro 2001). The results reported in this paper demonstrate the importance of hydrodynamics in nutrient dynamics of seagrass beds and provide evidence for applicability of mass-transfer relationships derived from engineering studies to understanding biogeochemical processes. 
Acknowledgements. We wish to thank the many people who assisted with field work, including T. Bolton, G. Delozier, J. Lartigue, and A. Gunter. Thanks also the staff at the Dauphin Island Sea Laboratory and Dr. K. Fanning's laboratory (USF) for analysis of seawater samples. We also wish to thank the staff at the H. T. Stone Memorial Park in St. Joseph Bay for their assistance, and 3 anonymous reviewers. Research support was provided by a NSF PECASE award (OCE-9996361) to F.I.M.T.

\section{LITERATURE CITED}

Ackerman JD, Okubo A (1993) Reduced mixing in a marine macrophyte canopy. Funct Ecol 7:305-309

Atkinson MJ, Bilger RW (1992) Effects of water velocity on phosphate uptake in coral reef-flat communities. Limnol Oceanogr 37:273-279

Baird M, Atkinson MJ (1997) Measurement and prediction of mass transfer to coral reefs. Limnol Oceanogr 42: 1685-1693

Bilger RW, Atkinson MJ (1992) Anomalous mass transfer of phosphate on coral reef flats. Limnol Oceanogr 37: 261-272

Carpenter RC, Hackney JM, Adey WH (1991) Measurements of primary productivity and nitrogenase activity of coral reef algae in a chamber incorporating oscillatory flow. Limnol Oceanogr 36:40-49

Cornelisen CD, Thomas FIM (2002) Ammonium uptake by seagrass epiphytes: isolation of the effects of water velocity using an isotope label. Limnol Oceanogr 47:1223-1229

Denny MW (1988) Biology and the mechanics of the waveswept environment. Princeton University Press, Princeton, NJ

Duarte CM, Chiscano CL (1999) Seagrass biomass and production: a reassessment. Aquat Bot 50:21-36

Duarte CM, Piro O (2001) Interdisciplinary challenges and bottlenecks in the aquatic sciences. Limnol Oceanogr Bull 10:57-60

Eckman JE (1987) The role of hydrodynamics in recruitment, growth, and survival of Argopecten irradians (L.) and Anomia simplex (D'Orbigny) within eelgrass meadows. J Exp Mar Biol Ecol 106:165-191

Fonseca MS, Fisher JS (1986) A comparison of canopy friction and sediment movement between four species of seagrass with reference to their ecology and restoration. Mar Ecol Prog Ser 29:15-22

Fonseca MS, Kenworthy J (1987) Effects of current on photosynthesis and distribution of seagrass. Aquat Bot 27:59-78

Fonseca MS, Fischer JS, Zieman JC, Thayer GW (1982) Influence of the seagrass, Zostera marina L., on current flow. Estuar Coast Mar Sci 15:351-364

Gacia E, Granata TC, Duarte CM (1999) An approach to measurement of particle flux and sediment retention within seagrass (Posidonia oceanica) meadows. Aquat Bot 65: 255-268

Gambi MC, Nowell ARM, Jumars PA (1990) Flume observations on flow dynamics in Zostera marina (eelgrass) beds. Mar Ecol Prog Ser 61:159-169

Gerard VA (1982) In situ water motion and nutrient uptake by the giant kelp Macrocystis pyrifera. Mar Biol 69:51-54

Glasgow HBJ, Burkholder JM (2000) Water quality trends

Editorial responsibility: Kenneth Heck (Contributing Editor), Dauphin Island, Alabama, USA and management implication from a five-year study of a eutrophic estuary. Ecol Appl 10:1024-1046

Grizzle RE, Short FT, Newell CR, Hoven H, Kindblom L (1996) Hydrodynamically induced synchronous waving of seagrasses: 'monami' and its possible effects on larval mussel settlement. J Exp Mar Biol Ecol 206:165-177

Hearn CJ, Atkinson MJ, Falter JL (2001) A physical derivation of nutrient-uptake rates in coral reefs: effects of roughness and waves. Coral Reefs 20:347-356

Hurd CL, Harrison PJ, Druehl LD (1996) Effect of seawater velocity on inorganic nitrogen uptake by morphologically distinct forms of Macrocystis integrifolia from wavesheltered and exposed sites. Mar Biol 126:205-214

Koch EW (1994) Hydrodynamics, diffusion-boundary layers and photosynthesis of the seagrasses Thalassia testudinum and Cymodocea nodosa. Mar Biol 118:767-776

Koch EW, Gust G (1999) Water flow in tide- and wavedominated beds of the seagrass Thalassia testudinum. Mar Ecol Prog Ser 184:63-72

Larned ST, Atkinson MJ (1997) Effects of water velocity on $\mathrm{NH}_{4}$ and $\mathrm{PO}_{4}$ uptake and nutrient-limited growth in the macroalga Dictyosphaeria cavernosa. Mar Ecol Prog Ser 157:295-302

Moncreiff CA, Sullivan MJ, Daehnick AE (1992) Primary production dynamics in seagrass beds of Mississippi Sound: the contributions of seagrass, epiphytic algae, sand microflora, and phytoplankton. Mar Ecol Prog Ser 87:161-171

Morin J, Morse JW (1999) Ammonium release from resuspended sediments in the Laguna Madre estuary. Mar Chem 65:97-110

Nikora VI, Suren AM, Brown SLR, Biggs BJF (1998) The effects of the moss Fissidens rigidulus (Fissidentaceae: Musci) on near-bed flow structure in an experimental cobble bed flume. Limnol Oceanogr 43:1321-1331

Oldham CE, Lavery PS (1999) Porewater nutrient fluxes in a shallow fetch-limited estuary. Mar Ecol Prog Ser 183: $39-47$

Patterson MR (1992) A chemical engineering view of cnidarian symbioses. Am Zool 32:566-582

Staver LW, Staver KW, Stevenson JC (1996) Nutrient inputs to the Choptank River estuary: implications for watershed management. Estuaries 19:342-358

Strickland JDH, Parsons TR (1972) A practical handbook of seawater analysis. Fisheries Research Board of Canada, Ottawa, p 121-125

Thomas FIM, Atkinson MJ (1997) Ammonium uptake by coral reefs: effects of water velocity and surface roughness on mass transfer. Limnol Oceanogr 42:81-88

Thomas FIM, Cornelisen CD, Zande JM (2000) Effects of water velocity and canopy morphology on ammonium uptake by seagrass communities. Ecology 81:2704-2713

Verduin JJ, Backhaus JO (2000) Dynamics of plant-flow interactions for the seagrass Amphibolis antarctica: field observations and model simulations. Estuar Coast Mar Sci 50: 185-204

Williams SL, Carpenter RC (1998) Effects of unidirectional and oscillatory water flow on nitrogen fixation (acetylene reduction) in coral reef algal turfs, Kaneohe Bay, Hawaii. J Exp Mar Biol Ecol 226:293-316

Worcester SE (1995) Effects of eelgrass beds on advection and turbulent mixing in low current and low shoot density environments. Mar Ecol Prog Ser 126:223-232

Submitted: February 22, 2002; Accepted: October 4, 2002 Proofs received from author(s): December 19, 2002 